http://dx.doi.org/10.5007/1981-1322.2017v12n2p133

\title{
Uso do software GeoGebra para desenvolver conhecimentos acerca de algumas propriedades da circunferência
}

\author{
The use of GeoGebra to develop knowledge about some circumference properties
}

\author{
Hiago Portella de Portella \\ hiagoportella@yahoo.com.br \\ José Carlos Pinto Leivas \\ leivasjc@unifra.br
}

\begin{abstract}
Resumo
Este artigo é um fragmento de uma pesquisa mais ampla e teve por objetivo utilizar a tecnologia para verificar a apropriação de propriedades de circunferência, como tangentes e cordas, as quais são fundamentais para desenvolver o conhecimento matemático e do raciocínio lógico em Geometria, no Ensino Fundamental, por meio de uma atividade realizada numa escola da rede municipal em Júlio de Castilhos, RS. Optou-se por utilizar o software livre GeoGebra para desenvolver a pesquisa, a qual caracterizou-se como um estudo de caso, de natureza qualitativa. Apresenta-se uma das atividades propostas e resolvidas, a qual é descrita e analisada de acordo com os pressupostos teóricos utilizados. Considerou-se a importância desse software como ferramenta para o ensino de Geometria, na escola básica, auxiliando na passagem dos esquemas mentais concretos para o abstrato. Concluiu-se que os alunos compreenderam e apropriaram-se de conceitos como o de circunferências concêntricas, relacionando, no decorrer da resolução, conhecimentos próprios. Além disso, essa tecnologia computacional influenciou o processo de ensino aprendizagem de um tópico de Geometria Euclidiana, possibilitando ao professor inovar na busca de uma aprendizagem significativa.
\end{abstract}

Palavras-chave: Tecnologia e educação matemática; Software GeoGebra; Ensino Fundamental; Geometria.

\begin{abstract}
This article is a fragment of a larger research and aimed to use the technology to verify the appropriation of circumference properties, such as tangents and circumference ropes, which are fundamental to develop mathematical knowledge and logical reasoning in Geometry in Elementary School, through an activity carried out at city of Júlio de Castilhos, RS. It was chose to use GeoGebra to develop the research, which was characterized as a case study of qualitative nature. We present one of the activities proposed and solved, which is described and analyzed according to the theoretical assumptions used. It was considered the importance of this software as a tool for the teaching of Geometry, in the basic school, aiding in the passage from the concrete mental schemes to the abstracts. It was concluded that the students understood and appropriated concepts such as concentric circles, relating, in the course of the resolution, their own knowledge. Besides that, this computational technology influenced the teaching and learning process of a topic of Euclidean Geometry, enabling the teacher to innovate in the search for meaningful learning.
\end{abstract}

Keywords: Technology and mathematics education; software GeoGebra; Elementary School; Geometry.

\section{Introdução}

Ao analisar pressupostos sobre o cenário educacional brasileiro, por meio de dados divulgados pelo Sistema de Avaliação da Educação Básica (Saeb), o qual tem por objetivo 
promover o diagnóstico do sistema educacional brasileiro, dos fatores associados ao desempenho do estudante, sendo composto por um conjunto de avaliações mantidas e sob responsabilidade do Instituto Nacional de Estudos e Pesquisas Educacionais (Inep), verifica-se que tal cenário traz à tona os resultados referentes à Prova Brasil. Nele, destacaram-se índices preocupantes em vista da educação brasileira, apontando a necessidade de uma intensa e importante reflexão a respeito do ensino nos últimos anos, especialmente da Educação Básica (BRASIL, 2016).

De acordo com Kilpatrick (1992, p.74, trad. dos autores), “[...] as investigações em Educação Matemática, nos anos 60 e 70, cresceram não somente em número, senão também na amplitude com que os investigadores se moviam entre os limites das disciplinas, superando as fronteiras dos países."

A realidade educacional exposta nos resultados do Saeb convida a buscar novas possibilidades e novas formas de ensinar, inclusive, por meio da inserção de tecnologias no cenário educacional, como instrumento de aprendizagem, conectando o que acontece fora da sala de aula com o ambiente da escola. Mas a tecnologia não deve exercer o papel principal nesse contexto, uma vez que o aluno precisa ser o foco do processo, tendo o professor como mediador, o qual apresenta situações que o motivam para o desenvolvimento de uma aprendizagem significativa (KENSKI, 2007; FUJITA; RODRIGUES, 2016; TENÓRIO; OLIVEIRA; TENÓRIO, 2016).

O uso de tecnologias computacionais na educação proporciona transformações, estruturais e funcionais, interferindo, não apenas no que se faz, mas também na forma como os sujeitos se relacionam com o mundo. Isso possibilita novas maneiras de ler, escrever e pensar, estimulando diversos aspectos como criatividade, interatividade, entre outros, favorecendo a compreensão de conceitos, propriedades e representações. Tais tecnologias apresentam novas possibilidades para contribuir com o processo de ensino aprendizagem, propiciando a interdisciplinaridade e a seleção dos conhecimentos disponibilizados aos alunos, para que os mesmos se transformem em sujeitos reflexivos, que apliquem a tecnologia com sabedoria (KENSKI, 2007; RIBEIRO; GRAVINA, 2013; CORRÊA, 2016).

Colette Laborde, um dos membros da equipe do Cabri, um dos softwares pioneiros de Geometria Dinâmica, ao indicar várias possiblidades da tecnologia, a inclui como elemento fornecedor de coleta de dados, o que ocorre para muitos professores, e isso não muda o fazer da 
tarefa matemática. Para ela, os softwares de Geometria Dinâmica oferecem maior autonomia para os estudantes, em especial quanto ao modo de exploração do conteúdo em desenvolvimento na sala de aula. Em termos de novas espécies de tarefas, ela indica:

- tarefas nas quais o ambiente permita estratégias eficientes, as quais não sejam possíveis em um ambiente apenas com papel-e-lápis;

- tarefas levantadas pelo contexto computacional, ou seja, as que podem ser realizadas somente nesse ambiente. (LABORDE, 2001, p. 301, trad. dos autores)

Para a Matemática, o processo de desenvolvimento do raciocínio lógico-matemático e da aprendizagem significativa é formado por aspectos educacionais que podem ser viabilizados por meio de atividades que estimulem o aluno a atuar sobre seu conhecimento. Nesse contexto, apresenta-se a Geometria Dinâmica, cuja riqueza de possibilidades, para relacionar conceitos e representações simbólicas, requer uma forma específica de raciocinar. Assim, a possibilidade de estudar e compreender, com o auxílio de construções geométricas em programas de Geometria Dinâmica, tais como o software livre GeoGebra, apresenta novas perspectivas para o entendimento dos conteúdos básicos de Matemática. Especificamente em Geometria, satisfaz-se a necessidade de desenvolver o conhecimento matemático para ser ensinado e aprendido, transformando o saber científico em saber escolar, intermediados pela tecnologia (BRASIL, 1997; CARGNIN; BARROS, 2015; GIMENES; FREITAS, 2015; SILVA; KRINDGES, 2012;).

Em relação aos resultados do Saeb referentes a proficiência média em Matemática, destaca-se o desempenho tímido, no período de 2005 a 2015, com uma evolução de 240 para 256 pontos, respectivamente, ficando abaixo dos índices esperados de 300 a 350 pontos, considerados adequados para o ensino fundamental - anos finais. Esse sistema de avaliação considera que os alunos apresentam um nível insuficiente de conhecimento de conteúdo, de habilidades e de competências em Matemática. O estudo justifica-se por meio de tais indicadores, os quais apontam que os conhecimentos matemáticos demonstrados pelos alunos de $9^{\circ}$ ano estão distantes do mínimo esperado para a conclusão do ensino fundamental (BRASIL, 2016; FUJITA; RODRIGUES, 2016).

Além disso, os softwares de Geometria Dinâmica apresentam, em sua interface, os entes matemáticos, substituindo a régua, o compasso e o papel que são, tradicionalmente, utilizados no ambiente escolar. Permitem que os estudantes substituam essas ferramentas tradicionais, 
proporcionando uma clara visualização da construção desenvolvida, viabilizando sua desconstrução ou reconstrução, além de oportunizar a retomada do processo de construção sem prejuízos ou perdas de etapas. Nesse sentido, enfatiza-se que a visualização, uma característica do pensamento humano, contribui para o desenvolvimento do raciocínio intuitivo, desencadeando a capacidade de representar objetos mentalmente (GERÔNIMO, BARROS; FRANCO, 2010; NASCIMENTO, 2012).

A partir disso, expõe-se uma atividade realizada no GeoGebra, com alunos do Ensino Fundamental, com o objetivo de utilizar a tecnologia para verificar a apropriação de propriedades de circunferência, como tangentes e cordas, as quais são fundamentais para o desenvolvimento do conhecimento matemático e do raciocínio lógico em Geometria.

A seguir, apresenta-se uma síntese histórica e cronológica do desenvolvimento da Geometria como uma ciência organizada e sistematizada ao longo de quase três milênios.

\section{Geometria}

As primeiras sociedades organizadas desenvolveram a Matemática a partir de atividades básicas, como fazer a distribuição de água e de terras para a agricultura e construir edificações, o que possibilitou o desenvolvimento de novas profissões, tais como a dos construtores e administradores, os quais orientavam a distribuição das terras, a semeadura, a colheita e controlavam os estoques de alimentos, dando origem a uma aristocracia detentora de conhecimento (FONTES, 1969; BOYER, 1974).

Com o desenvolvimento do pensamento organizado surgiu, também, a Geometria como ciência prática aplicada à vida, inicialmente de forma intuitiva e experimental, a partir das necessidades sociais e administrativas. No entanto, com Euclides, (300 a.c.), a Geometria tornouse sistematizada, evoluindo como uma área sólida e incontestável da Matemática, fundamentando-se em hipóteses, sendo demonstrada logicamente. Na obra Os Elementos, Euclides organizou-se e reúne os conhecimentos existentes acerca de Geometria, em uma coleção de papiros, contendo definições, axiomas, teoremas e postulados de uma maneira sistemática que, até então, não existia (FONTES, 1969; BOYER, 1974; DETONI; PINHEIRO, 2016).

O pensamento euclidiano dominou o universo acadêmico e científico por muitos séculos, entretanto, em meados do século XVII, com o surgimento do Renascimento, o pensamento 
humano passou por profundas transformações, inclusive sobre o pensamento matemático. Descartes (1596-1650) e Fermat (1601-1665), dois matemáticos contemporâneos que jamais trabalharam juntos inventaram uma geometria capaz de representar o mundo de uma maneira diferente, a Geometria Analítica, cujos fundamentos estavam de acordo com a Geometria Euclidiana. Destacam-se, também, outros matemáticos, como Leibniz (1646-1716), que estudaram a Geometria Analítica e a aproximação da Álgebra, dando significados a operações algébricas através da linguagem geométrica (HEFEZ, 1985; SANTOS, 2011).

Até o século XIX, a Geometria Euclidiana foi aceita como única, porém estudos de Lobachevsky (1793-1856) inauguraram uma nova perspectiva de se perceber o universo e demonstraram, de maneira incontestável, que havia outras possibilidades de interpretar e utilizar o postulado das paralelas, desenvolvendo-se uma das Geometrias Não-Euclidianas, ligadas a princípios diferentes dos estabelecidos por Euclides. Essas geometrias não negavam a anterior e apresentavam novas possibilidades de conhecimento para, mais tarde, a comunidade científica explicar fenômenos físicos como a Teoria da Relatividade de Einstein, a Mecânica Quântica, entre outras (FONTES, 1969; BOYER, 1974).

Porém, as Geometrias Não-Euclidianas continuariam à margem científica por várias décadas, sendo reabilitadas pelos notáveis estudos de G. B. B. Riemann (1826-1866), o qual generalizou as descobertas de Lobachevsky a ponto de torná-las um caso particular, em qualquer número de dimensões, em qualquer tipo de espaço, chamado Riemanniano, onde o euclidiano é apenas um caso particular (BOYER, 1974).

No próximo item, apresenta-se uma caracterização da Geometria Dinâmica e sua importância para o ensino.

\subsection{As tecnologias, no contexto escolar, e a Geometria Dinâmica}

As tecnologias computacionais estão presentes na vida cotidiana das pessoas por meio da interação das redes sociais de comunicação e da evolução dos produtos e dos equipamentos de modo geral, influenciando o mundo em que se vive, sendo os alunos nativos nesse mundo tecnológico. Com isso, a escola começa a absorver os benefícios disponibilizados por computadores, tablets, celulares de alta complexidade, entre outros. Ao aproveitar o interesse natural dos estudantes pela tecnologia, utilizando-a no espaço escolar para proporcionar uma 
aprendizagem ativa e reflexiva, isso impulsiona a educação para o desenvolvimento da capacidade investigativa, oportunizando a descoberta do conhecimento pelos discentes e desafiando os docentes a enriquecer a sua aula, criando situações para instigar o aluno a valer-se da informação para elaborar a sua visão do mundo, crítica e reflexiva, deixando de ser apenas um consumidor de informação (KENSKI, 2007; NASCIMENTO, 2012; CORRÊA, 2016; TENÓRIO; OLIVEIRA; TENÓRIO, 2016).

Nesse sentido, faz-se necessário que as escolas e, consequentemente, os professores, se adequem a essa realidade, promovendo aulas dinâmicas e transformando a sala de aula em ambientes informatizados, não se restringindo apenas a laboratórios de informática, mas introduzindo, em suas aulas, aparelhos de celulares smartphone, tablet, entre outros, capazes de conectar-se à internet e softwares educacionais, uma vez que essa se constitui numa fonte de informação. Dessa forma, buscam-se suportes tecnológicos para explorar os novos recursos digitais e novas fontes de pesquisa, extrapolando os livros didáticos. Essa nova perspectiva didática acaba por valorizar os conhecimentos prévios dos alunos em relação ao uso desses instrumentos tecnológicos, tendo o professor como o mediador entre o conhecimento matemático e a interatividade tecnológica (SANTOS; MACÊDO, 2015).

Assim, apresentam-se como instrumentos pedagógicos auxiliares ao ensino, em especial na área de Geometria, os programas computacionais, entre eles, os softwares de Geometria Dinâmica, que permitem a interação e experimentação de conteúdos intuitivamente e com agilidade. De acordo com Corrêa (2016), ao recorrer às tecnologias computacionais, o professor também exerce o papel de orientador, ensinando e aprendendo junto com o aluno, ao interpretar as linguagens, que se modificam constantemente, e as formas de expressar o conhecimento, buscando maneiras de relacionar a teoria e a prática pedagógica, a qual acaba por ser revitalizada.

A entrada de instrumentos computacionais, nas salas de aula, tais como os softwares de Geometria Dinâmica, possibilita propor uma 'nova' Geometria, com novas ferramentas, permitindo mudanças, disponibilizando o movimento de elementos em uma construção geométrica e possibilitando novos caminhos, diferentes das soluções tradicionais restritas ou únicas. "Isso predispõe os aprendizes de Geometria a uma prática investigativa, autônoma e produtiva" (DETONI; PINHEIRO, 2016). 
Para todos os efeitos, entende-se por Geometria Dinâmica a geometria da régua e compasso, em um ambiente computacional o qual operacionaliza a experimentação das relações entre os objetos geométricos, com suas construções e movimentações de forma interativa, criativa, ou seja, dinâmica.

\section{Percurso metodológico}

A atividade foi proposta a alunos da Escola Municipal de Ensino Fundamental Élio Salles, em Júlio de Castilhos, no Rio Grande do Sul, sendo realizada, no ambiente da referida escola, na forma de um grupo de estudos. Os alunos participantes, do nono ano, foram escolhidos aleatoriamente e se disponibilizaram a participar. Esses são identificados na pesquisa como Aluno A, Aluno B e Aluno C. Para desenvolver a atividade, os Alunos A e C utilizaram o notebook e o Aluno B, um tablet.

Optou-se pelo software livre GeoGebra (www.GeoGebra.org) para realização das atividades, o qual é um programa computacional educativo de Geometria Dinâmica, para ser utilizado em sala de aula, disponível gratuitamente em diferentes idiomas, sendo esse um dos fatores que contribuíram para sua escolha como objeto de pesquisa.

A investigação caracterizou-se como um estudo de caso definido, delimitado e com interesse próprio no estudo de Geometria no Ensino Fundamental com o uso de tecnologias. Conforme André; Ludke (1986) e Fiorentini; Lorenzato (2007), o caso é um sistema delimitado, tratado como único, o qual apresenta características singulares que retratam uma realidade específica e merecem um investimento investigativo do pesquisador.

Uma vez que os resultados da pesquisa foram obtidos a partir da descrição e do contato direto do pesquisador com os alunos, enfatizando o processo em detrimento do produto, optou-se pela interpretação qualitativa pois, com o desenvolvimento da investigação, foram descritas as situações, transcritos os diálogos, os desenhos e as figuras extraídas das atividades. Segundo André, Lüdke (1986) e Moreira (2011), isso caracteriza a natureza interpretativa dos dados, centrando-se na análise dos significados e das ações dos sujeitos envolvidos gerando novas reflexões a cada passo dado.

No próximo item, apresenta-se a atividade realizada pelos alunos no software GeoGebra, e, a seguir, sua descrição e análise dos resultados. 


\subsection{Atividade}

Essa atividade teve como objetivos específicos a apropriação de conceitos, de algumas propriedades e de resultados de Geometria Euclidiana, relacionados à circunferência no plano, e a investigação da funcionalidade das ferramentas e comandos do software GeoGebra. Destaca-se que os comandos e ferramentas próprias do software estão descritos entre aspas.

A partir desses, foram fornecidos comandos para a realização da atividade para comprovar o seguinte resultado: dadas duas circunferências concêntricas, toda corda da circunferência maior, que é tangente à circunferência menor, é dividida ao meio no ponto de tangência (Figura 1).

Figura 1: Circunferências concêntricas

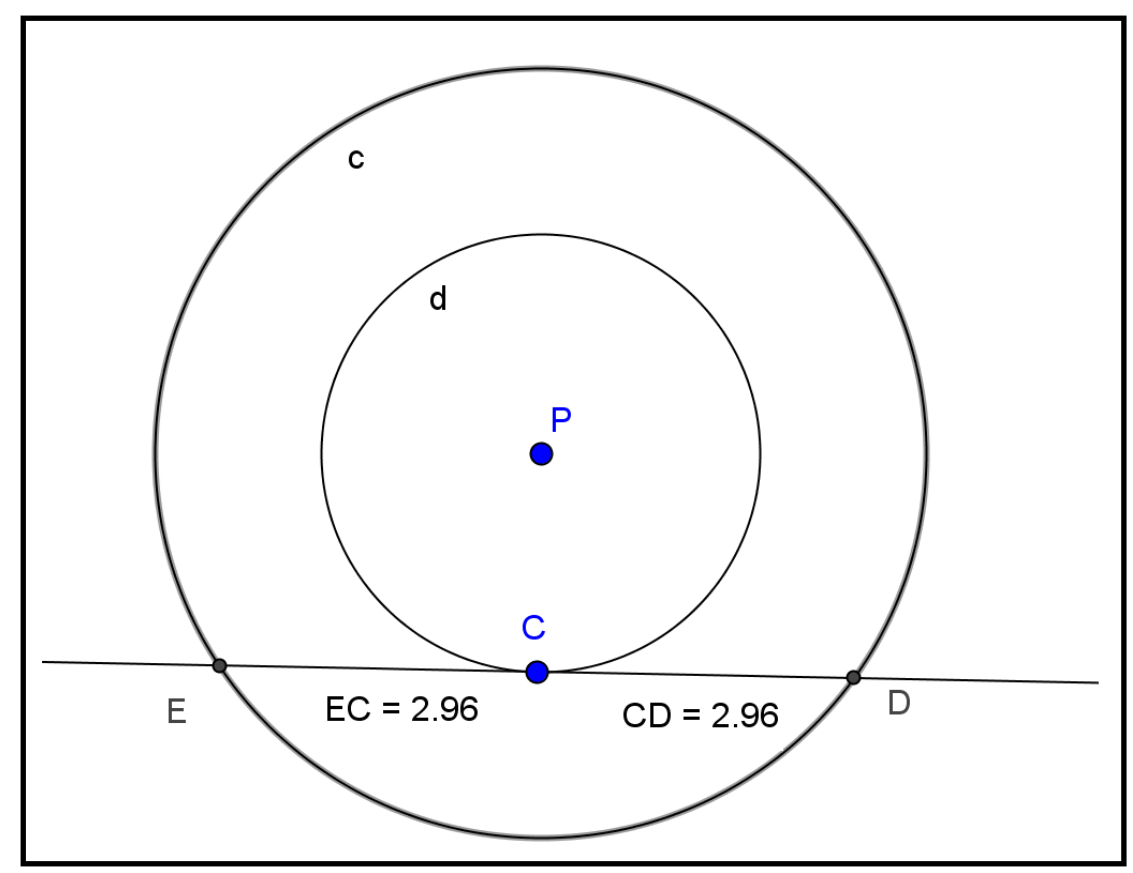

Fonte: Elaboração dos autores.

Os estudantes foram incentivados a seguir as orientações impressas em uma folha de oficio, como descritas a seguir: criar um arquivo do GeoGebra. Com a ferramenta "Círculo dados centro e um ponto", construa uma circunferência $c$ de centro A, passando pelo ponto B e, com a mesma ferramenta, construa uma circunferência $d$ de centro $\mathrm{A}$, passando pelo ponto $\mathrm{C}$, localizado no interior de $c$. Renomeie o ponto A como P. Com a ferramenta "Reta tangente", determine a tangente a d, passando por C. O software mostra duas retas tangentes. Esconda uma delas e o ponto B. Use a ferramenta "interseção de dois objetos" para determinar a interseção da 
circunferência $d$ com a reta tangente. Assim, são construídos os segmentos EC e CD. Descubra uma ferramenta no GeoGebra para medir esses segmentos. Essas medidas comprovam o resultado acima? Mova o ponto $\mathrm{P}$ e descreva o que acontece com os segmentos EC e CD.

\section{Descrição e análise dos resultados}

A atividade foi resolvida por meio da comprovação visual, utilizando o software GeoGebra, sendo necessária a retomada de outras propriedades relativas à circunferência, vistas em outras atividades realizadas em encontros anteriores.

O Aluno A iniciou o desenvolvimento da sua construção com uma circunferência $c$ de centro $\mathrm{P}$, passando pelo ponto $\mathrm{B}$ e a circunferência $d$, concêntrica a $c$, passando pelo ponto $\mathrm{C}$. A seguir, construiu a reta $b$, tangente à $d$, interceptando $c$ nos pontos $\mathrm{B}$ e D. Com a ferramenta "interseção de dois objetos", determinou o ponto E de interseção da circunferência $d$ com a reta tangente $b$. Usando a ferramenta "distância, comprimento ou Perímetro" calculou as medidas dos segmentos BE, ED e BD (Figura 2).

Figura 2: Circunferências concêntricas, com protocolo de construção - Aluno A

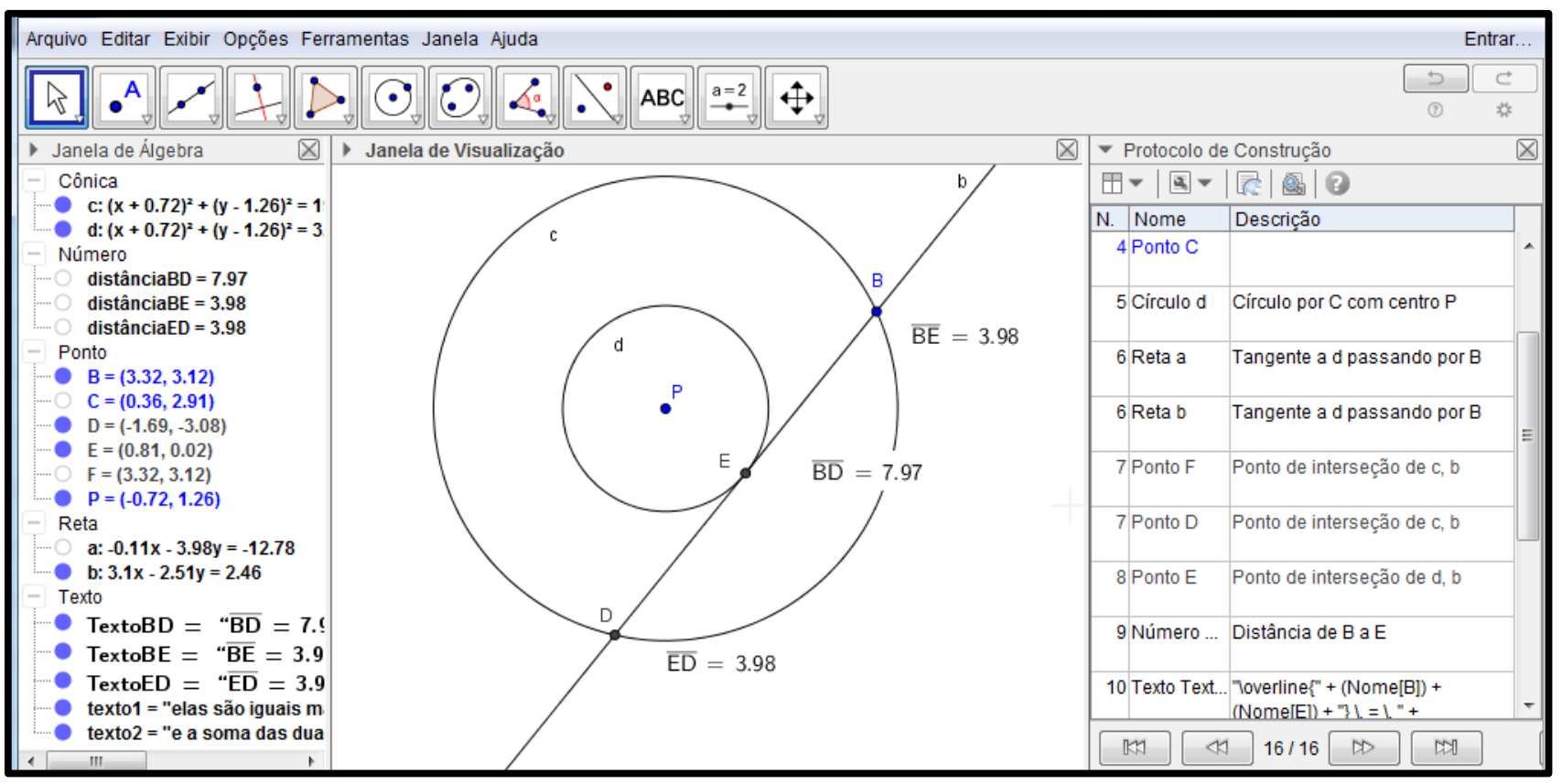

Fonte: Acervo da pesquisa. 
O aluno concluiu que as medidas BE e ED são iguais e que, quando movimentava a figura construída, essas medidas permaneciam iguais. Além disso, sua soma corresponde à medida do segmento BD.

O Aluno B construiu a circunferência $c$ de centro $\mathrm{P}$, passando pelo ponto $\mathrm{D}$, e a circunferência $d$, concêntrica a $c$, passando pelo ponto $\mathrm{C}$, conforme a Figura 3. Construiu as retas $a$ e $b$, tangentes à $d$, interceptando $c$ no ponto D. Com a ferramenta "interseção de dois objetos", determinou o ponto de tangência $\mathrm{A}$, o ponto $\mathrm{E}$ de interseção entre a circunferência $c$ e a reta $b$ e, consequentemente, o segmento DE, que é corda de $c$. Com a ferramenta "distância, comprimento e perímetro", determinou as medidas dos segmentos AE e DA, as quais valem a metade da medida do segmento DE.

Observa-se, assim, que, por meio de atividades realizadas mentalmente e relacionadas à criatividade, os Alunos A e B apresentaram resoluções matemáticas em que as regras e os procedimentos foram aplicados sem aprofundamento teórico, estando baseados apenas em aspectos figurais e conceituais.

Figura 3: Circunferências concêntricas com corda, com protocolo de construção - Aluno B

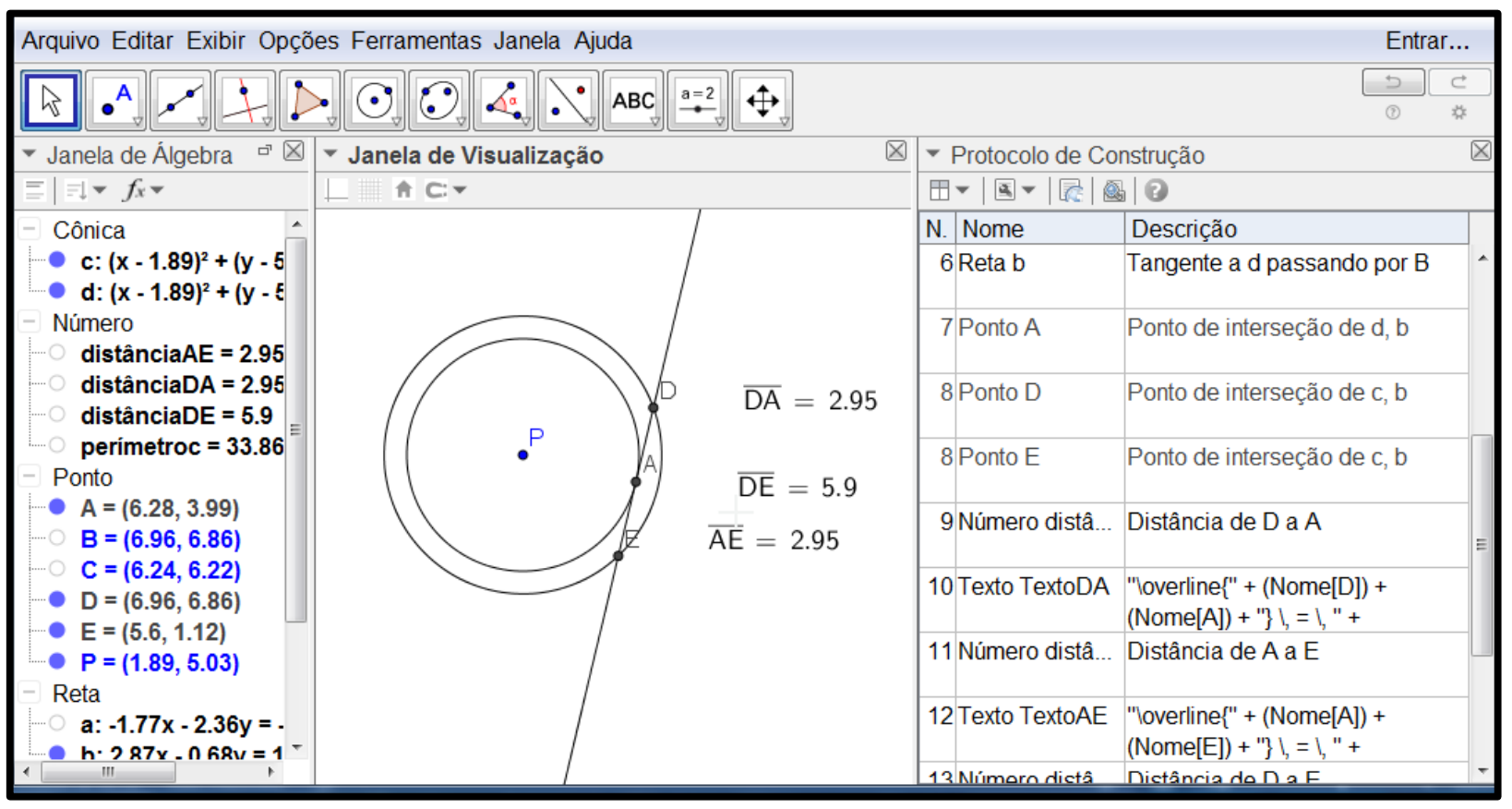

Fonte: Acervo da pesquisa. 
O Aluno $\mathrm{C}$ construiu a circunferência $c$ de centro $\mathrm{P}$, passando pelo ponto $\mathrm{B}$, e a circunferência $d$, concêntrica a $c$, passando pelo ponto $\mathrm{C}$, escondendo os pontos $\mathrm{B}$ e $\mathrm{C}$. Construiu a reta $a$, tangente à $d$. Com a ferramenta "interseção de dois objetos", determinou os pontos E de interseção entre a circunferência $d$ e a reta tangente $b$ e os pontos D e F, de interseção da reta com a circunferência $c$ (Figura 4). Usando a ferramenta "distância, comprimento ou Perímetro", calculou as medidas dos segmentos DE e EF. O aluno concluiu que as medidas DE e EF são iguais, pois a corda EF foi dividida ao meio, no ponto de tangência, e que, ao movimentar a figura construída para a direita, elas ficaram indefinidas.

Figura 4: Construção do Aluno C com protocolo de construção

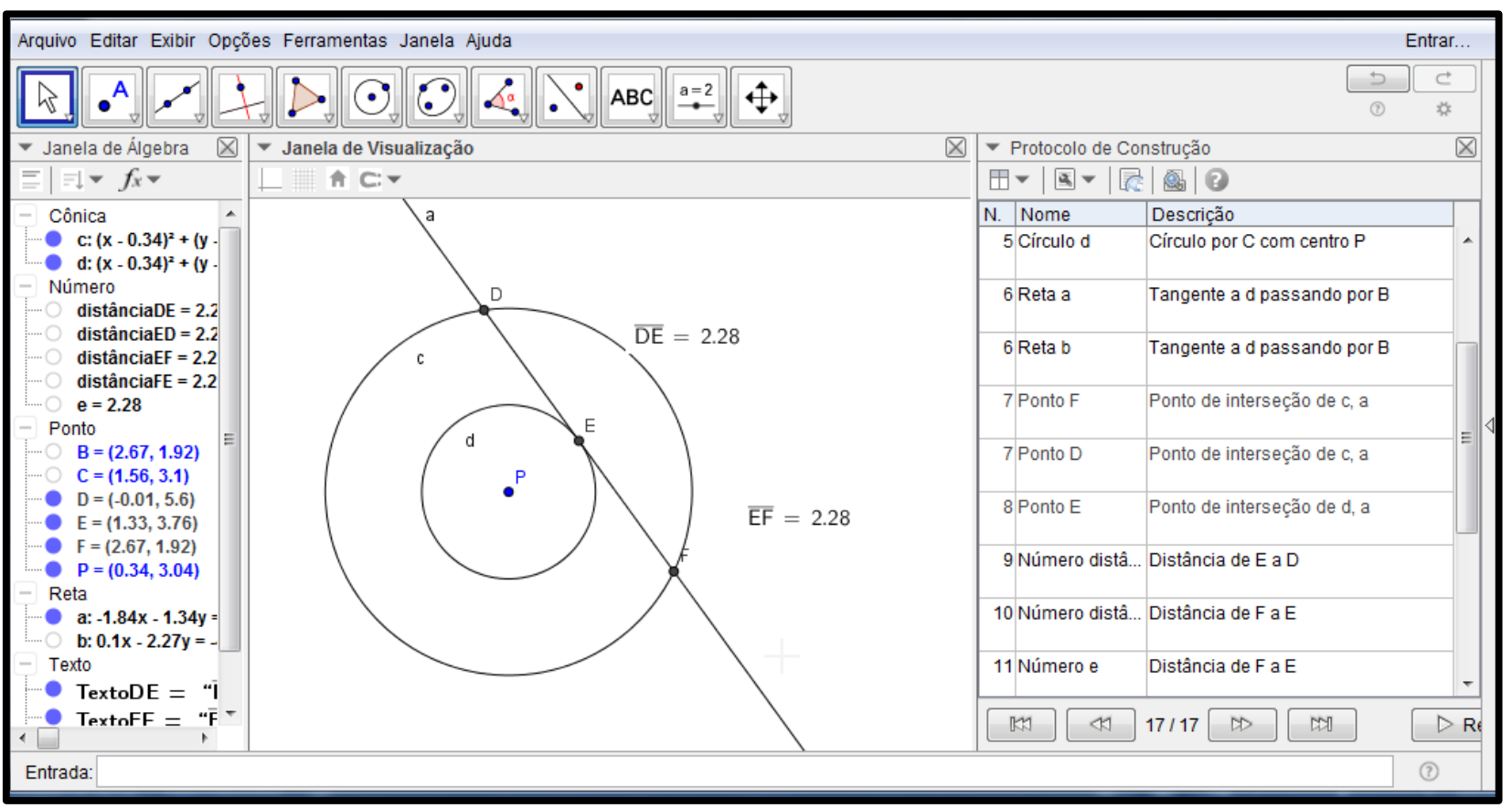

Fonte: Acervo da pesquisa.

Dessa forma, verificou-se, na sua resolução, o uso da visualização, a qual consiste em habilidade, processo e produto de criação, para interpretar figuras ou imagens pela mente humana, com o auxílio de ferramentas tecnológicas, com a finalidade de desenhar e comunicar informações, para desenvolver ideias não conhecidas e avançar na compreensão do conhecimento geométrico (ARCAVI, 1999).

Analisando a solução dos Alunos A e B, percebeu-se que desenvolveram a atividade corretamente, recorrendo aos conceitos de circunferências concêntricas, reta tangente e corda que 
já haviam sido estudados em uma atividade anterior. O Aluno A teve um pouco de dificuldade para medir os segmentos BE, ED e BD construídos, uma vez que o software apresenta a ferramenta com o nome de "distância, comprimento ou perímetro", e não especificamente com o nome "medir segmento". Após algumas tentativas frustradas, ele conseguiu medir os segmentos em questão. A dificuldade do Aluno B, em utilizar a ferramenta de medir, foi por estar resolvendo a atividade com o tablet, pois como tinha de marcar os pontos com o dedo na tela, houve problemas relacionados à precisão na marcação, sendo essa uma limitação apresentada pelo mesmo.

Com relação ao Aluno C, infere-se que também resolveu a atividade corretamente, mas, em sua conclusão, percebeu que, se a circunferência maior passasse a ser menor que a outra, as medidas dos segmentos seriam indefinidas, isto é, a relação de tangencia desapareceria. Sobre as medidas dos segmentos DE e EF, percebeu que, quando a construção é movimentada, elas mudam, mas permanecem iguais, ou seja, medem a metade da medida do segmento DF. De acordo com Gimenes; Freitas (2015), a ferramenta "mover" apresenta ao estudante a possibilidade de perceber as variações de medidas, contribuindo na análise da proposição. Entretanto, ele não usou uma ferramenta do software para medir o segmento DF.

Conforme corroboram XXXX e Ferreira (2015), o raciocínio geométrico, desencadeado no decorrer da atividade, foi analisado e interpretado a partir da perspectiva da visualização dos alunos frente à tecnologia, como recurso para compreender a formação de conceitos abstratos e a elaborar as resoluções para as atividades. Percebeu-se que, ao conhecerem as ferramentas do GeoGebra, os alunos se convenceram com mais facilidade de que o resultado é verdadeiro, sendo que ainda propiciou ao professor vantagens do software. Dessa forma, buscou-se entender a fundamentação axiomática e os teoremas envolvidos, aliados à dedução intuitiva na obtenção dos resultados de modo consistente.

\section{Considerações finais}

No que se refere aos objetivos específicos da atividade, verificou-se que os alunos compreenderam e se apropriaram do conceito de circunferências concêntricas, relacionando, no decorrer da resolução, conhecimentos da própria bagagem, como de segmento, de ponto médio de um segmento, de interseção, de retas tangentes e de cordas. Observa-se que o raciocínio 
geométrico desencadeado no decorrer dessa resolução foi analisado e interpretado a partir da perspectiva da visualização dos alunos frente à tecnologia, como recurso para compreender a formação de conceitos abstratos e elaborar as resoluções.

Com relação ao processo de elaborar a resolução da atividade, verifica-se que haveria muita dificuldade para determinar, com precisão, a reta tangente a circunferência menor, pois com o uso da régua e do compasso seria necessária a construção de outras circunferências e de outras retas para chegar à determinação dessa tangente. Também seriam necessárias mais construções envolvendo circunferências e retas para verificar que a corda, referida na atividade, é dividida ao meio, ou seja, que ela intercepta a circunferência menor no ponto médio. Além disso, um erro de construção colocaria em dúvida a resposta final. Assim, o uso das ferramentas disponíveis no software facilitou o desenvolvimento das construções geométricas e colaborou para a exatidão da resposta envolvendo as propriedades da circunferência, contribuindo para o desenvolvimento da abstração e a comunicação do conhecimento geométrico.

Sobre as conclusões a que chegaram os estudantes, observou-se a importância do GeoGebra como ferramenta para favorecer o ensino de Geometria na escola básica, pois possibilitou aos educandos uma fonte de enriquecimento cognitivo. Além disso, entendeu-se que o software auxiliou a passagem dos esquemas mentais concretos para o abstrato, na medida em que se exigiu mais ou menos abstração na sequência de atividades. Por meio da visualização da imagem concreta, se esperava chegar à abstração do raciocínio geométrico, interligando conceitos já conhecidos mediados pelo software, coordenando informações e levantando hipóteses para criar novas soluções, o que de fato parece ter sido alcançado até onde se percebeu.

Conclui-se que as tecnologias computacionais influenciaram o processo de ensino aprendizagem de Geometria Euclidiana, nos indivíduos investigados, pois não limitaram a resolução da atividade a uma resposta fechada e permitiram a interação com todas as etapas do processo resolutivo, explorando uma ideia antes de estudar o seu conceito, avançando e retrocedendo a cada passo dado, permitindo uma visão geral do desenvolvimento da atividade, proporcionando uma aprendizagem significativa para eles. Em relação ao professor, houve a possibilidade de inovar sua prática pedagógica ao estabelecer uma conexão entre as tecnologias computacionais envolvidas (software, tablete, notebook) e os registros no protocolo do GeoGebra. Comprovou, além disso, contribuições ao processo educacional, levando à 
conscientização sobre ouso desses recursos como coautores da aprendizagem, aprendendo a dominar a tecnologia inserida, agora, na escola, especialmente, peloo envolvimento dos alunos na pesquisa.

\section{Referências}

ANDRÉ, M. E. D. A.; LÜDKE, M. Pesquisa em educação: Abordagens qualitativas. São Paulo: EPU, 1986.

ARCAVI, A. The role of visual representation in the learning of mathematics. In: NORTH AMERICAN CHAPTER OF THE PME, 1999. Proceedings... Acesso em: 30 set. 2016.

BOYER, C. B. História da Matemática. São Paulo: Universidade de São Paulo, 1974.

BRASIL. Secretaria de Educação Fundamental. Parâmetros curriculares nacionais: Matemática / Secretaria de Educação Fundamental. Brasília: MEC / SEF, 1997.

BRASIL. Sistema de Avaliação da Educação Básica. Edição 2016. Resultados. Disponível em: <http://portal.inep.gov.br/artigo/-/asset_publisher/B4AQV9zFY7Bv/content/inep-apresenta-resultados-dosaeb-prova-brasil-2015/21206>. Acesso: março de 2017.

CARGNIN, C.; BARROS, R. M. O. A contribuição do GeoGebra para a compreensão do conceito de convergência. Revista Paranaense de Educação Matemática. Campo Mourão, v. 4, n. 6, p. 215-232, 2015.

CORRÊA, A. A. A alfabetização tecnológica docente: uma ferramenta da educação. Educação $\begin{array}{llllll}\text { Matemática Pesquisa. } & \text { São } & \text { Paulo, } & \text { v. } & 18 . & \text { Disponível: }\end{array}$ <http://revistas.pucsp.br/index.php/emp/article/view/26073>. Acesso: setembro 2016.

DETONI, A. R.; PINHEIRO, J. M. L. Compreensões Filosóficas para Uma Alternativa do Pensamento Geométrico. REVEMAT. Florianópolis, v. 11. Disponível em: <https://periodicos.ufsc.br/index.php/revemat/article/view/1981-1322.2016v11nespp232>

Acesso: março 2016.

FONTES, H.C. d'O. No passado da Matemática. Rio de Janeiro: Fundação Getúlio Vargas, 1969.

GERÔNIMO, J. R.; BARROS, R. M. O.; FRANCO, V. S. Geometria Euclidiana plana: um estudo com o software GeoGebra. Maringá: Eduem, 2010.

GIMENES S. S.; FREITAS, R. C. O. Desenvolvimento do raciocínio geométrico: uma experiência com o GeoGebra. Revista Eletrônica Debates em Educação Científica e Tecnológica, v. 05, n. 02, p. 49-66, Outubro, 2015. Disponível em: <http://ojs.ifes.edu.br/index.php/dect/article/viewFile/448/307>. Acesso em: 11 nov. 2015.

KENSKI, V. M. Educação e tecnologias: O novo ritmo da informação. Campinas: Papirus, 2007. 
KILPATRICK, J., Historia de la investigación em educación matemática. In: Educación Matemática e Investigación. Kilpatrick, J., Rico, L., Sierra, M. (org,). Madrid: Editorial Síntesis S.A., 1992.

LABORDE, C. Integration of technology in the design of geometry tasks with Cabri-Geometry. International Journal of Computers for Mathematical Learning 6. Netherlands: Kluwer Academic Publishers, 2001, pp. 283-317.

XXXX

NASCIMENTO, E. G. A. Actas de la Conferencia Latinoamericana de GeoGebra: Proposta de uma nova aplicação como instrumento psicopedagogica na escola: O LABGG (Laboratório GeoGebra), 2012. Disponível

em: <https://www.researchgate.net/profile/Eimard_Nascimento/publication/280684062_Proposta_de_uma_no va_aplicao_como_instrumento_psicopedagogica_na_escola_o_LABGG_(Laboratrio_GeoGebra)/links/55 c1344308ae092e96684121.pdf>. Acesso em: 24 abr. 2016.

RIBEIRO, R. S.; GRAVINA, M. A. Disco de Poincaré: uma proposta para Explorar Geometria Hiperbólica no GeoGebra. Professor de Matemática Online. 2013, n. 1, v. 1. Disponível em: <http://pmo.sbm.org.br/v001/n001/sbm-pmo-v001-n001-ribeiro-e-gravina.pdf>. Acesso em: 5 jun. 2014.

SANTOS, A. C. F.; MACÊDO, J. A. Uso dos Softwares GeoGebra e Winplot no Estudo de Funções Transcendentes. REVEMAT. Florianópolis, v. $10 . \quad$ Disponível em: <https://periodicos.ufsc.br/index.php/revemat/article/view/38981/31152>

Acesso: março 2016.

SANTOS, I. N. Explorando conceitos de Geometria Analítica Plana utilizando Tecnologias da Informação e Comunicação: uma ponte do Ensino Médio para o Ensino Superior construída na formação inicial de Professores de Matemática. Dissertação Universidade Federal de Ouro Preto, 2011. 163 p.

SILVA, N. G.; KRINDGES, A. Geometria dinâmica GeoGebra - Uma nova maneira de ensinar. $1^{\text {a }}$. Conferência Latino Americana de GeoGebra.ISSN 2237- 9657, 2012. Disponivel em: <http://revistas.pucsp.br/index.php/IGISP/article/view/8296/7228>. Acesso em: setembro de 2016

TENÓRIO, A.; OLIVEIRA, R.; TENÓRIO, T. Mapeamento da inserção das tecnologias de informação e comunicação na prática de ensino de professores de matemática. Educação Matemática Pesquisa. São Paulo, v.18, 2016. Disponível: <http://revistas.pucsp.br/index.php/emp/article/view/24032>. Acesso: setembro 2016.

Recebido em 18/04/2017 - Aceito em 13/11/2017 